\title{
Sem Grana, o Turista Vai para o Brejo?
}

\section{Without Money, the Tourist Goes to the Brejo?}

\author{
Fabiana Gama de Medeiros \\ Universidade Federal da Paraíba - UFPB - Brasil \\ fabiana@ccsa.ufpb.br \\ ORCID: 0000-0002-1414-3745 \\ Thiago Moraes \\ Universidade Estadual do Piauí - UESPI - Brasil \\ thgmoraes@gmail.com \\ ORCID: 0000-0001-9729-4858
}

Submetido em 12/06/2019; Aprovado em 31/10/2019

\begin{abstract}
Resumo
Contexto: O Brejo paraibano tornou-se um destino turístico atraente por ser uma região de clima serrano no interior do estado da Paraíba e vem se configurando como um local ideal para quem busca sossego, atividades culturais e ar puro. A região conta com o Fórum Regional de Turismo Sustentável do Brejo Paraibano, que visa a estimular a Rota Cultural Caminhos do Frio, no entanto o evento enfrenta o dilema da redução dos recursos financeiros por parte do Governo do Estado, o que afeta a sua execução. Objetivos de ensino: Promover o debate entre os alunos sobre o dilema da escassez do recurso financeiro e impelir soluções de ação para o Fórum, considerando que as propostas podem afetar todos os agentes envolvidos e a credibilidade do Fórum. Fontes de dados: 0 caso é real e os dados do caso são oriundos de dados primários, obtidos a partir de entrevistas e observações em campo, bem como de dados secundários. Contudo, alguns diálogos foram simulados para ilustrar a situação. Aplicação: 0 caso pode ser utilizado em disciplinas de graduação e pós-graduação (latu sensu), nos cursos de Administração, Turismo e de Gestão Pública que discutam um ou mais dos seguintes temas: regionalização do turismo; planejamento do turismo (em circuitos turísticos regionais); turismo e desenvolvimento local e regional; marketing turístico e marketing de lugares.
\end{abstract}

Palavras-chave: Rota Cultural Caminhos do Frio. Marketing de Lugares. Desenvolvimento Turístico. Caso para Ensino.

\begin{abstract}
Context: The Brejo Paraibano has become an attractive tourist destination due to its mountainous climate, located in the countryside of Paraíba. It has become an ideal place for those seeking tranquility, cultural activities and fresh air. The region has the Regional Sustainable Tourism Forum of Brejo Paraibano, which aims to stimulate the Cultural Route "Caminhos do Frio", however, the event faces a dilemma concerning the reduction of the State's Government financial resources, which affects its execution. Teaching goals: Promoting a debate amongst students regarding the dilemma on scarcity of financial resources and to impel solutions for courses of action for the Forum, considering that the proposals affect all involved stakeholders and thus the Forum's credibility. Data source: This teaching case is real and its data comes from primary data, gathered through interviews and field observations, and also from secondary data. Nonetheless, some dialogues were simulated in order to illustrate the context. Applicability: This teaching case is suitable for subjects in both undergraduate and graduate level, on Management, Tourism and Public Management courses that discuss one or more of the following topics: regionalization of tourism; tourism planning (in regional tourism circuits); tourism and local and regional development; tourism marketing and place marketing.

Keywords: Cultural Route "Caminhos do Frio". Place Marketing. Tourism Development. Teaching Case.
\end{abstract}




\section{Introdução}

Em junho de 2019, começa, em Areia, a 14a edição da Rota Cultural Caminhos do Frio, homenageando o centenário de Jackson do Pandeiro, músico paraibano nascido em Alagoa Grande, cidade que compõe a rota. 0 evento turístico-cultural ocorre anualmente entre os meses de julho e agosto, envolve as cidades de Bananeiras, Solânea, Areia, Pilões, Alagoa Nova, Alagoa Grande e Serraria, na região do Brejo da Paraíba, e é organizado pelo Fórum Regional de Turismo Sustentável do Brejo Paraibano (uma instância de governança regional do turismo). Em uma das suas últimas reuniões antes do início do evento, o Fórum se depara com a notícia da retirada do aporte de recursos por parte do governo estadual. Como nem tudo são flores, em 2015, faltando pouco tempo para o início da Rota Cultural, o que os gestores do Fórum devem fazer para viabilizar o evento, a despeito da falta de patrocínio do governo estadual?

\subsection{0 brejo paraibano}

- Cem anos? Já?

Repentinamente, ele aparece e pergunta assustado sem saber onde estava nem com quem falava. Eis que sentado num banquinho de couro de bode, um jovem músico vive em sonho seu maior desejo: 0 de conhecer o ídolo.

- Se...se...seu Jackson? Sim, sim, sim, seu Jackson, ce...cem anos! Se..seu aniversário! E vamos fazer uma festa pro senhor. Uma festa bem grande que, inclusive, vai passar aqui na sua cidade, Alagoa Grande.

O jovem respondeu assustado, emocionado...e gaguejando muito. Era um sonho. Lá, ele tocava a canção "Lágrima”, de Jackson do Pandeiro. Tocava soturnamente numa versão melancólica e lamentava ser novo demais e nunca ter conhecido pessoalmente o músico que o inspirou. Mas o sonho lhe deu essa chance. Enquanto tocava, repentinamente, o cantor entrara no cômodo em que jovem dedilhava seu violão e perguntara assustado por que havia passado tanto tempo dormindo.

- Mas, meu jovem! Por que ninguem me acordou? Tanta música eu já poderia ter feito! Tantas moças cortejado e tantos lugares visitado!

- Seu Jackson, não me pergunte por que não sei, mas estou muito pulando de contente em conhecer o senhor. Isso sim estou, visse? Logo agora que vamos lhe homenagear na Rota Cultural do Caminhos do Frio. É a oportunidade da minha vida de até mesmo tocar junto com o senhor.

- Rota Cultural? Caminhos do Frio? Mas o que é isso?

- Huuumm! Faz sentido sua surpresa. Então vou contar, puxe esse banquinho aí, segura o pandeiro um pouco e escuta só...

- Tô ouvindo!

- A microrregião do Brejo Paraibano, que é essa que nós estamos, é uma das 23 microrregiões da Paraíba, faz parte da mesorregião do Agreste Paraibano. Tem uma população que foi calculada, em 2014, pelo IBGE, que é a instituição que tem essa informação. 0 senhor sabe né? Tem mais de 116 mil habitantes e está dividida em nove municípios (Alagoa Grande, Alagoa Nova, Areia, Bananeiras, Borborema, Matinhas, Pilões, Solânea e Serraria), como aqui nesse mapa, olhe só! (Figura 1, em anexo).

- Tá bom, mas que rota é essa mesmo?

- Seu Jackson, ela acontece nas cidades localizadas em lugares mais altos (com mais de 500m acima do nível do mar), é uma espécie de caminho a se percorrer pelas cidades do Brejo Paraibano. São cidadezinhas todas lindas e que encantam os turistas pelas suas temperaturas mais amenas, porque nos invernos mais frios, as temperaturas podem chegar a até $12^{\circ}$. É um clima bucólico, cheio de belezas naturais e paisagens lindas. Além da beleza natural, o Brejo Paraibano faz sucesso pela sua diversidade cultural em termos de artes, música e gastronomia, evidenciada em diferentes roteiros e eventos culturais promovidos na região como a Rota Cultural Caminhos do Frio.

- Tô gostando disso. Fale mais!

- Bem! Não há mais muito o que falar, é uma festa que vai durar de 01 de julho a 01 de setembro desse ano. É a $14^{\underline{a}}$ vez que acontece e esse ano, vamos homenagear o senhor pelo seu centenário. Tem comida, friozinho bom, gente alegre e bonita e muita música, claro! Vamos 
lá?

- Vamos sim, mas ainda tenho uma dúvida?

- Qual, seu Jackson?

- Cem anos? Já?

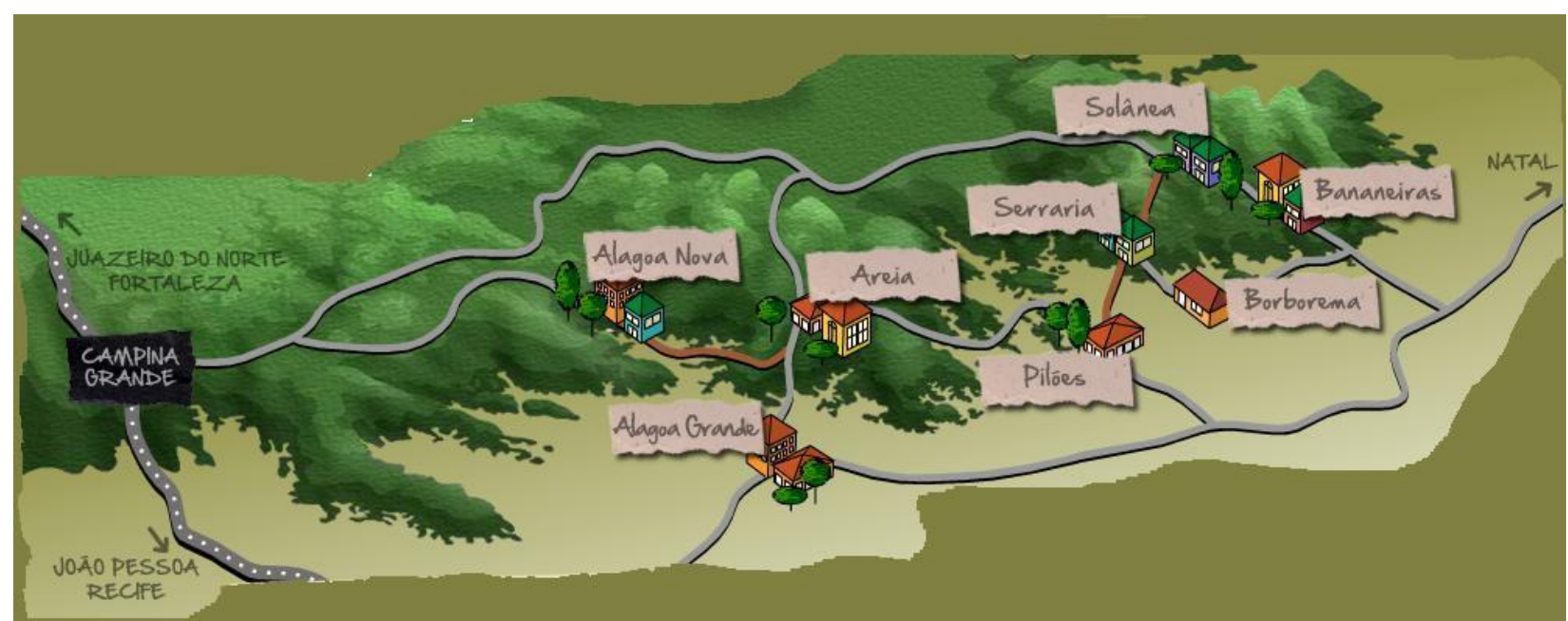

Figura 1: Rota - Localização da Região do Brejo

Fonte: https://caminhosdofrio.blogspot.com/2011/07/programa-se-circuito-do-frio-de-18-de.html

\subsection{Impulsionando o turismo no brejo}

O Brejo Paraibano faz parte do processo de regionalização do turismo no estado, resultado da implantação do Programa de Regionalização do Turismo - Roteiros do Brasil, pelo Ministério do Turismo. O Fórum Regional do Turismo Sustentável do Brejo Paraibano (FRTSBP) é uma Instância de Governança Regional, dentro das diretrizes operacionais do Programa Nacional de Regionalização do Turismo.

O histórico da formação do Fórum Regional de Turismo Sustentável do Brejo Paraibano parte do convênio firmado, em 2004, entre a Secretaria do Estado de Turismo e Desenvolvimento Econômico (SETDE/PB) e o Ministério do Turismo. O Fórum possui como membros representantes do poder público, do terceiro setor e da sociedade civil organizada dos municípios componentes da região Turística do Brejo Paraibano. No entanto, somente uma parte dos municípios inseridos na região turística do Brejo participam do Fórum.

0 motivo fundamental é que, em sua maioria, os municípios não possuem políticas de turismo local, o que gera dificuldade em participar do Fórum. Assim, o Fórum é composto por representantes do Sebrae, do governo estadual, do setor privado, da sociedade civil e das prefeituras das cidades de Bananeiras, Solânea, Areia, Pilões, Serraria, Alagoa Nova, Alagoa Grande e Remígio. Os objetivos do Fórum são: criar uma interlocução regional para a operacionalização do Programa de Regionalização do Turismo - Roteiros do Brasil; coordenar o processo da regionalização do turismo na região do Brejo Paraibano; e descentralizar as ações de coordenação do processo, deslocando-as do Estado ou da União para a região do Brejo Paraibano.

O Fórum implantou o projeto "Roteiros do Brejo Paraibano", para promover o uso do território regional, considerando aspectos históricos e culturais da região, como o Roteiro Caminhos dos Engenhos, Roteiro Civilização do Açúcar, Roteiro Caminhos do Frio e Roteiro nos Passos do Padre Ibiapina. Desses roteiros, o mais consolidado na região é o Roteiro Caminhos do Frio, cujos agentes envolvidos apresentam uma participação ativa nas atividades do Fórum.

\subsection{Rota cultural caminhos do frio - que caminho seguir?}

0 projeto "Caminhos do Frio - Rota Cultural”, Figura 2, recebe dezenas de apresentações culturais, oficinas, festival gastronômico e trilhas ecológicas e esportivas. Cada cidade envolvida no projeto sedia o evento por uma semana durante os meses de julho e agosto. 0 evento recebe por volta de 200 mil pessoas nesse período com um crescimento médio anual de $20 \%$ nesse público, dados de 2018.0 festival é realizado pelo Fórum com apoio da PBTur (Empresa Paraibana de Turismo), do Sebrae, da Atura (Associação Turística, Cultural e Rural de Areia) e das prefeituras dos municípios participantes do 
evento, promovendo um incremento de $30 \%$ na geração de empregos durante a realização do evento.

Contudo, a vida nem sempre foi fácil para a Rota. No ano de 2015, a menos de 15 dias para o início do evento um fato abalou a organização: o Fórum recebeu a notícia de que nenhum tipo de apoio financeiro seria disponibilizado por parte do Governo Estadual, em função de dificuldades financeiras que o governo enfrentava devido ao combate à crise no abastecimento de água na região. Diante disso, na época, a diretoria do Fórum convocou uma reunião para discutir com os membros o que poderia (se é que algo poderia) ser feito.

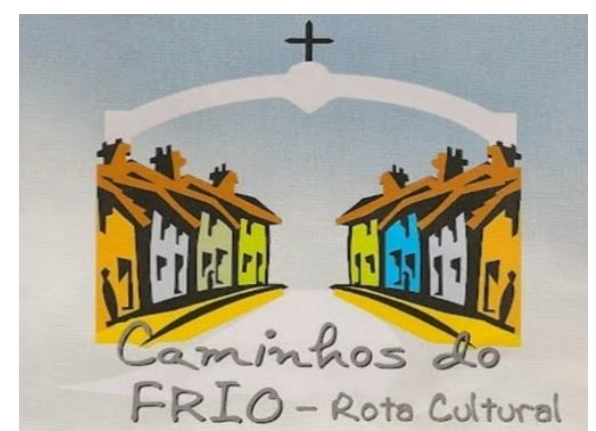

Figura 2 - Logo Caminhos do Frio

Fonte: www.brejoparaibano.com.br

\section{- A reunião de 2015}

Na reunião, estavam o presidente do fórum e os membros da diretoria, prefeitos e secretários de turismo/cultura das cidades de Alagoa Nova, Alagoa Grande, Bananeiras, Solânea, Pilões e Serraria, representante da ATURA (Associação Turística de Areia), e representantes do Sebrae. Uma discussão levantada pelos representantes das prefeituras foi a falta de apoio da população para o evento, inclusive com algumas pessoas enxergando o evento como um gasto desnecessário diante da crise (principalmente de recursos hídricos) na qual os municípios estavam passando.

- Senhores, temos uma insatisfação popular que precisamos administrar, e ela vem crescendo.

Afimou um dos prefeitos presentes nos primeiros momentos da reunião, ratificando informações de que muitas pessoas estavam considerando que a prefeitura poderia encontrar uma forma melhor de direcionar o dinheiro público, que não fosse no evento, e que este não era visto como prioridade naquele momento pela população que estava sem água. Ali, ele demonstrava preocupação com o destino do evento e um possível boicote popular. Ele pergunta:

- O que vamos fazer? E se todo mundo resolver não comparecer ao evento? E o pior é que o governo do estado retirou boa parte da verba necessária para plena execução da rota justamente por isso: pelo problema do abastecimento. A população apoiou a decisão e nós não temos como bancar nossa etapa sozinhos, a prefeitura não tem força financeira para levar sozinha nossa semana no evento, pelo menos a minha prefeitura não.

Ao que um dos gestores do Sebrae, presente na reunião aponta o dilema:

- A Rota Cultural Caminhos do Frio sempre teve o apoio financeiro do governo do estado, e o projeto sempre se sustentou basicamente com esse investimento. Caso vocês decidam, em virtude disto, por não realizar o evento, a região do Brejo pode perder a visibilidade e os benefícios em termos de atividade turística que o evento traz, já que ele se tornou uma marca registrada da região.

\section{E continua:}

- Por outro lado, se decidirem por realizá-lo, podem ter problemas como incapacidade de atender à demanda turística, não oferecer atrações culturais, agravar a crise de abastecimento de água, as dívidas dos municípios, o que pode denegrir a imagem da região como um destino turístico. É uma faca dedois gumes,mas precisamos tomar uma decisão, urgente!

Nesse momento, de uma coisa, no entanto, a diretoria do Fórum não tinha dúvidas: teria que tomar 
essa decisão em conjunto com os presentes na reunião naquele mesmo dia, pois a data do evento se aproximava, e, ocorrendo ou não, as medidas cabíveis teriam que ser tomadas o mais rápido possível. 0 que fazer? Continuar com o evento sem o apoio do Governo do Estado ou suspender e correr os riscos envolvidos? 


\section{NOTAS DE ENSINO}

O caso relata a situação vivenciada pelo Fórum Regional do Turismo Sustentável do Brejo Paraibano diante do fato do governo estadual não patrocinar a Rota Cultural Caminhos do Frio no ano de 2015. 0 texto traz muitos problemas comuns para gestores de turismo que estão sob a dependência de recursos públicos para promover atividades e eventos turísticos em suas regiões. No contexto do caso, é importante que os alunos recomendem o curso de ação do Fórum, pesando a potencial gravidade da situação em termos de como as decisões tomadas podem afetar todos os agentes envolvidos, inclusive a reputação do Fórum.

\subsection{Fontes de dados}

O caso é real e os dados do caso são oriundos de dados primários, obtidos a partir de entrevistas e observações em campo, bem como de dados secundários oriundos de sites de prefeituras e governo, Sebrae, atas das reuniões do Fórum e trabalhos científicos. Contudo, alguns diálogos foram simulados para ilustrar a situação.

\subsection{Aplicação}

O caso pode ser utilizado em disciplinas dos cursos de Administração, Turismo e de Gestão Pública que discutam um ou mais dos seguintes temas:

- Regionalização do turismo

- Planejamento do turismo (em circuitos turísticos regionais)

- Turismo e desenvolvimento local e regional

- Marketing turístico

- Marketing de lugares

\subsection{Objetivos de ensino}

Espera-se que o estudante, ao ler, analisar e discutir o caso, desenvolva a capacidade de avaliar situações complexas da gestão do turismo e formule alternativas de ação, pesando os prós e contras em diversos aspectos e levando em consideração as consequências de cada decisão para os diferentes envolvidos.

\subsection{Questões de estudo sugeridas}

1. Por que a diretoria do Fórum se encontra com o problema descrito no caso? Que elementos contribuíram para essa situação?

2. Identifique os principais públicos envolvidos na situação e o que está em jogo para cada um deles.

3. O que a diretoria do Fórum deveria fazer? Descreva não só o que deve ser feito, mas também como. Por exemplo: quais ações são necessárias para que a decisão tenha os resultados esperados?

4. Que contribuições um evento como o Caminhos do Frio pode trazer para o desenvolvimento local e regional de regiões como a do Brejo paraibano?

\subsection{Análise teórica}

\section{- Planejamento turístico}

0 turismo é uma das maiores indústrias do mundo representando mais de $10 \%$ do mercado de trabalho do mundo, $11 \%$ do PIB mundial, e de acordo com previsões, o número de viagens a turismo irá chegar a 1,6 bilhões até 2020 (Olivier, Karangwa \& Muragizi, 2012).

Portanto, o turismo abre possibilidades para o aproveitamento de características locais, dentre elas históricas, culturais, físicas e econômicas promovendo-as e criando uma identidade para a região. Nesse sentido, os reflexos gerados pela atividade turística podem ser percebidos tanto pelo aumento dos níveis de qualidade de vida, na identificação dos agentes locais de um senso de pertença, quanto pela exclusão e marginalização da comunidade em relação aos resultados positivos advindos do turismo.

A população local precisa querer o turismo, sabendo que este pode gerar benefícios econômicos com a injeção de capital e benefícios sociais e oportunidades de empregos diretos ou indiretos (Macêdo \& Ramos, 2013). Assim, caso a atividade atue em conjunto com o seu entorno, seus impactos positivos e 
demais benefícios, como a inclusão social e o desenvolvimento local, poderão de fato ocorrer. Na medida em que a comunidade local tiver possibilidade de trabalhar com o turismo, maiores serão as vantagens competitivas para o setor (Baptista \& Moreira, 2013).

Uma das estratégias de organização da atividade turística de forma regionalizada são os Circuitos Turísticos. Estes são modelos espaciais apresentados em forma de "pacotes", construídos por atrativos turísticos de uma região com o objetivo de fazer com que o turista passe por várias cidades, oferecendo experiências e atrativos naturais e/ou culturais. Esse modelo integrado de roteiro estimula as cidades participantes a se organizarem para a oferta de infraestrutura e equipamentos turísticos de qualidade (Fuini, 2011).

Assim foi criada a Região Turística do Brejo Paraibano, composta por 14 municípios e gerenciada pelo Fórum Regional de Turismo Sustentável do Brejo Paraibano, dando vida ao processo de regionalização do turismo no Estado, impulsionando e identificando espaços turísticos e contribuindo para a formatação de novos produtos.

O Fórum implantou o projeto "Roteiros do Brejo Paraibano" que contém um conjunto de ações que promovem o uso território regional considerando alguns aspectos históricos e culturais. 0 roteiro mais consolidado é o "Caminhos do Frio", com participação ativa dos agentes nas atividades do Fórum. No ano de 2015, o Fórum se deparou com um desafio nunca antes vivenciado: não recebeu nenhum tipo de apoio financeiro para a realização da Rota Cultural Caminhos do Frio por parte do Governo Estadual.

No contexto deste caso, o turismo é visto como um catalisador de desenvolvimento e de mudanças políticas e econômicas (Borma, 2015). Apesar de nem todas as regiões apresentarem potencialidades turísticas idênticas, elas assumem diferentes níveis de importância no desenvolvimento regional, com caráter de atividade dominante ou complementar. Desta forma, há um estímulo para a criação de bens e serviços com fins turísticos que beneficiem as populações locais e atenuem os desequilíbrios regionais.

0 turismo tem um importante papel na estratégia de preservação da história das localidades. Nelas, a comunidade é essencial na implantação de um plano para o desenvolvimento do turismo, se engajando e contribuindo para melhoria e divulgação dos atrativos de sua cidade.

\subsection{Roteiro para discussão}

Pode-se fazer a discussão em duas horas-aula ou em quatro horas-aula, e, conforme orientações de Roesch (2011), o texto deve ser encerrado com questões desafiadores a serem discutidas pelos estudantes. 0 Caso deve ser entregue com antecedência para que os alunos efetuem a leitura, principalmente quando há limitações de tempo em sala de aula

\section{- Para sessões de duas horas-aula:}

Os alunos devem ter suas questões respondidas individualmente, anteriormente à discussão do caso em sala de aula (as respostas podem contar como uma atividade, configurando-se como uma oportunidade para atribuir nota). A partir daí, a discussão segue com a formação de pequenos grupos e, posteriormente, no grande grupo, seguindo o roteiro que apresentaremos a seguir. Nessa configuração de aula, sugere-se a leitura prévia do caso.

\section{- Para sessões de quatro horas-aula:}

Nas primeiras duas-horas, aula o professor forma minigrupos (sorteados para promover maior interação entre a turma e retirar os alunos das zonas de conforto) para que a discussão ocorra dentro desses grupos. Durante a discussão nos pequenos grupos, o professor pode acompanhar os trabalhos, observando a participação e questionando.

Pode-se organizar os grupos em função da formação do aluno (quando a aplicação se der em turmas de pós-graduação). Os grupos também podem se reunir pelo perfil profissional do aluno (área de atuação no mercado de trabalho), por formação (graduação) e por linha de pesquisa em que se pode comparar as respostas de grupos homogêneos com os de heterogêneos.

O objetivo da resolução do caso em pequenos grupos é encontrar uma solução consensual, o que pode ser apresentado de duas formas: a) entregando as respostas para as questões sugeridas, ou b) elaborando um parecer técnico, com os seguintes itens: (1) Apresentação - contendo o objetivo do relatório e a equipe responsável; (2) Sumário executivo do caso - contendo a identificação dos principais elementos do caso, sintetizando o caso, o período, o contexto e os envolvidos; (3) Resolução das questões (lembrar de considerar o contexto do caso, não buscar informações atualizadas sobre o tema do caso - 
pelo menos nesse momento); (4) Dificuldades encontradas - apresentando as principais dificuldades encontradas durante a análise do caso (tais como falta de determinadas informações, a dificuldade na busca de consenso no grupo etc.) e destacando a importância do caso no desenvolvimento profissional do grupo.

Nesta fase da atividade, o professor pode valer-se de um formulário (Quadro 1) para avaliação individual e coletiva do desempenho dos alunos na resolução do caso. Não deve ser utilizada como única fonte de avaliação, é apenas um mecanismo de diagnóstico que serve tanto para balizar a nota quanto para dar um melhor feedback para os alunos.

\begin{tabular}{|l|l|}
\hline \multicolumn{1}{|c|}{ Capacidade de iniciativa } & Escore* \\
\hline $\begin{array}{l}\text { Atitude proativa e apresentação de alternativas e sugestões para providências voltadas para a resolução das } \\
\text { questões e melhorias das atividades exigidas na resolução do caso. }\end{array}$ & \\
\hline Participação de forma proativa das resolução do caso & \\
\hline Apresenta sugestões assertivas para a resolução do caso & Qualidade da resolução num dado intervalo de tempo, levando-se em conta a complexidade do trabalho, as \\
\hline Uso dos recursos à disposição (livros, artigos, teorias etc) & \\
\hline Execução do trabalho com qualidade compatível com os parâmetros estabelecidos (Escore coletivo). & \\
\hline Defesa do argumento de solução do caso com base na literatura. & \\
\hline TOTAL & \\
\hline
\end{tabular}

* Pontuação atribuída numa escala de 0 a 5.

Quadro 1: Formulário de avaliação do desempenho discente na solução do caso

Fonte: Elaboração própria (2016)

\section{Aquecimento - 10 minutos}

Pode-se iniciar a discussão solicitando que um ou mais alunos façam o resumo do caso de maneira breve. Também pode ser interessante perguntar se alguém já teve contato ou algum tipo de experiência com organizações similares a do caso.

\section{Organizando os fatos - 25 minutos (utilizar o quadro)}

No quadro 2, põe-se os principais agentes envolvidos no problema, para identificar as consequências de uma tomada de decisão. Esse quadro auxilia na discussão da questão 2.

\begin{tabular}{|l|l|l|l|l|}
\hline \multicolumn{1}{|c|}{ AGENTE } & $\begin{array}{c}\text { Tem influência } \\
\text { na decisão? }\end{array}$ & $\begin{array}{c}\text { Sofre impacto } \\
\text { da decisão? }\end{array}$ & $\begin{array}{c}\text { O que está } \\
\text { em jogo? }\end{array}$ & $\begin{array}{c}\text { Recursos } \\
\text { envolvidos }\end{array}$ \\
\hline Diretoria do Fórum de Turismo do Brejo & & & & \\
\hline Prefeituras e secretarias municipais & & & & \\
\hline Governo estadual & & & & \\
\hline Sebrae & & & & \\
\hline Empresas privadas do Brejo & & & & \\
\hline Residentes do Brejo & & & & \\
\hline Turistas & & & & \\
\hline
\end{tabular}

QUADR0 2: Agentes envolvidos no problema

Fonte: Elaboração própria (2016)

É possível mencionar atores mais específicos como imprensa, outros órgãos públicos, artistas, músicos, artesãos, hotéis, pousadas, restaurantes, pequenos comerciantes, e a própria ATURA pode ser destacada. Na coluna 'Recursos envolvidos', o aluno deve destacar qual(is) recurso(s) será(ão) utilizado(s) e qual(quais) gerará(ão) maior impacto na decisão; ele(s) pode(m) ser financeiro, humano, 
estrutural etc. Esse item possibilita uma reflexão sobre o uso dos recursos e, consequentemente, um melhor entendimento da gestão da escassez, o que dá suporte ao processo de tomada de decisão.

\section{Discussão do aspecto turismo - 25 minutos (utilizar o quadro)}

Para iniciar as discussões acerca do turismo, se faz interessante o levantamento de alguns objetivos que a diretoria do Fórum deve levar em consideração, como por exemplo (aspectos da questão 1 podem ser discutidos aqui):

- Garantir que o evento não se prejudique pela falta de patrocínio do governo estadual;

- Preservar a imagem e reputação do fórum e das cidades envolvidas;

- Encontrar outras fontes de financiamento e parcerias para a realização do evento;

- Aproveitar a situação para rever o formato de organização do evento;

- Repensar o papel do Fórum na organização do evento.

Esses desafios, que estão diante da diretoria do Fórum, levam a alguns questionamentos acerca da gestão do turismo (aspectos da questão 4 podem ser discutidos aqui):

- Em que medida a atividade turística deve ser patrocinada pelo poder público?

- É possível que a dependência dos recursos do poder público para a realização do evento tenha acomodado o Fórum, de modo que este deixou de considerar outras fontes de financiamento e parcerias (com o setor privado por exemplo)?

- Em várias cidades nordestinas, nos deparamos com a atividade turística acontecendo em concomitância com a falta de recursos básicos (saúde, saneamento, educação etc.) para a maioria da população. Como eventos como esse podem influenciar esses aspectos?

- De que maneira é possível analisar se os benefícios oriundos do evento são distribuídos de maneira justa para todos os agentes envolvidos (residentes, governo, setor privado, turistas...)?

\section{Discussão de alternativas - 30 minutos (utilizar o quadro)}

Ao se colocar na posição da diretoria do Fórum, os alunos devem levar em consideração alguns aspectos (a questão 3 pode ser discutida aqui):

- $\quad 0$ que fazer em relação ao Caminhos do Frio? Ir adiante mesmo assim ou cancelar o evento?

- Caso o evento seja cancelado, que consequências e impactos essa decisão pode acarretar?

- Caso seja decidido por proceder com o evento, que alternativas a diretoria do Fórum pode buscar para incentivar as cidades a promoverem o evento?

Decidir inicialmente por não realizar o evento parece uma alternativa extrema, dada sua importância para a região. Por outro lado, realizá-lo a qualquer custo teria um risco de sair algo errado e a Rota não acontecer de maneira satisfatória, gerando um boca a boca negativo. Uma solução intermediária passaria necessariamente por uma articulação do Fórum com cada uma das cidades envolvidas na Rota Cultural, observando suas necessidades e procurando soluções específicas.

É preciso também pensar em reavaliar a dependência do evento em relação a investimentos públicos, e levantar a possibilidade de que os próximos eventos fossem melhor planejados de maneira a focar em maiores aportes financeiros oriundos da iniciativa privada. Além disso, o envolvimento dos residentes de cada cidade no processo de planejamento poderia ser crucial para a apropriação do evento por parte da comunidade local.

Aconselha-se que, ao usar o quadro, o professor inicie escrevendo de um lado (esquerdo) o nome das cidades encadeados de cima para baixo em caixetas ou balões. Bem mais ao centro, os recursos exigidos e disponíveis a cada uma delas para realização do evento devem ser escritos da mesma forma. Ao lado direito dos recursos, ainda no centro do quadro, o professor deve elencar as necessidades existentes e em seguida (Direita), as soluções devem ser escritas conforme o debate vai evoluindo e as decisões vão surgindo.

O papel do professor é fazer, por meio de traços, os links entre as caixetas ou balões, ressaltando as influências, dependências e ligações existentes de um sobre o outro. Este recurso também pode ser construído como um mapa conceitual e, assim, pode adotar qualquer configuração, desde que a linha de raciocínio se mantenha condizente com a resposta esperada. 


\section{Comentários finais - 10 minutos}

Para terminar a aula, sugere-se perguntar aos alunos o que mais chamou a atenção no caso após toda a discussão e quais foram os principais aprendizados, reforçando os seguintes pontos:

- Desafios de planejamento de atividades turísticas, envolvendo diferentes agentes públicos, membros do setor privado, e diferentes interesses;

- "Concorrência" do financiamento da atividade turística com recursos básicos de infraestrutura de um lugar;

- Consideração dos residentes de um lugar no planejamento da atividade turística;

- Reflexões sobre as possíveis consequências do não acontecimento do evento.

\section{Bibliografia sugerida}

Baptista, L., \& Moreira, J. C. (2013). Parque Nacional dos Campos Gerais (PR) e turismo: um olhar através da comunidade local. Nature and Conservation, 6(1), 22-45.

Borma, A. (2015). Analysis of Tourism Indicators in Bihor County During 2007-2013. SEA-Practical Application of Science, 3(08), 109-115.

Brasil (2007). Ministério do Turismo. Módulo Operacional 3: Institucionalização da Instância de Governança Regional. Brasília: Ministério do Turismo.

Fuini, L. L. (2011). A Governança Territorial e Suas Manifestações: Arranjos Produtivos locais (APLS) e Circuitos Turísticos (Governance and territorial events: Local Productive Arrangements-APLs-and tours). Revista da Casa da Geografia de Sobral (RCGS), 13(1).

Macêdo, E. M., \& Ramos, R. G. (2013). O desenvolvimento do turismo em Barra Grande, Piauí (Brasil) e seu significado para a comunidade local. RITUR-Revista Ibero-americana de Turismo, 2(2), 89-107.

Militery Ngamata, O., Karangwa, A., Muragizi, I., \& Ngirincuti, H. (2012). Tourism industry and local development around the Volcanoes National Park in Rwanda. East African Journal of Science and Technology, (2), 59-66.

Roesch, S. M. A. (2011). Como narrar um caso para ensino. Revista Brasileira de Casos de Ensino em Administração, 2.

Scótolo, D., \& Netto, A. P. (2015). Contribuições do turismo para o desenvolvimento local. CULTUR-Revista de Cultura e Turismo, 9(1), 36-59.

Scotton, R. F. (2012). Gestão de projetos de turismo envolvendo recursos federais: o caso de Bento Gonçalves. 